Utility of the theory of planned behavior for predicting ...

\title{
Utility of the theory of planned behavior for predicting consumers' intentions toward involvement in co-creation activities
}

\section{Reem Refai Ahmed Mahmoud}

\section{Abstract}

The current study proposes an integrated framework to assess consumers' decisions toward involvement in cocreation. In doing so, the research extends the theory of planned behavior by incorporating emotions. In order to accomplish our research objectives a sample of 103 participants were recruited and between-subjects experimental design with two groups (treatment vs. control) were employed. The research instrument based on scenario manipulations and questionnaires. Hayes PROCESS models were utilized for data analyses. The results show that attitudes and emotions strongly influence consumers' intentions to engage in co-creation activities. Further, the hypothesized effects of subjective norms and perceived behavioral control were not confirmed. In conclusion, our research yielded significant theoretical and managerial implications. 
Utility of the theory of planned behavior for predicting ...

Reem Refai Ahmed Mahmoud

\section{Introduction}

Literature on customer co-creation and related concepts is diverse (Heidenreich et al., 2015, P.280). In 2014, Galvagno and Dalli summarized and classified the extant research related to the theory of value co-creation in an attempt to identify the different theoretical perspectives and research streams that characterize and define the co-creation literature. A similar extensive review of co-creation literature has also been done by other scholars such as Mustak et al. (2013). Cocreation is the practice of designing and developing new systems, products or services through active collaboration between an organization and its customers, employees and other stakeholders. It involves a frequent, interactive, bidirectional, and face-to-face communication between participants to jointly create value (Ramaswamy and Gouillart, 2010a; Gustafsson et al., 2012). Kambil and coauthors in their 1996 working paper "re-inventing value propositions" firstly coined the term "Co-creation". A further development in the concept has been made by Kambil and coauthors in their article "Explore the Power of the internet for Co-creation", published in Accenture's Outlook Magazine in 1999, where they defined co-creation as "engaging customers directly in the production or distribution of value" (Kambil et al. 1999, p. 40). Subsequent academic research in co-creation 
Utility of the theory of planned behavior for predicting ...

Reem Refai Ahmed Mahmoud

followed Kambil's work (i.e., Prahalad and Ramaswamy, 2000; Vargo and Lusch 2008; Gronroos \& Voima, 2013) highlighting the evolution and transformation of customers from passive audiences to active ones and emphasizing the importance of customers as co-creators of value and source of competencies.

\section{Research Questions and Objectives}

While recent academic research continues to devote considerable attention to customers' co-creation, what is missing from this research is a detailed investigation of the processes that shape consumers' decisions toward involvement in co-creation. The current study proposes a framework to assess consumers' decisions toward involvement in co-creation. In doing so, the research draws on extending the theory of planned behavior by incorporating additional predictors over and above the original theory predictors. To recap, this research aim is to answer our main research question stated below:

R.Q: What Are the Processes or Mechanisms Shaping Consumers' Decisions Toward Involvement in Co-Creation? 
Utility of the theory of planned behavior for predicting ...

Reem Refai Ahmed Mahmoud

\section{The Study in Context}

The current research addresses customers' co-creation experiences within the context of higher education institutions (HEI), particularly universities. Numerus well-established universities have recently tapped into this paradigm including for example the university of Adelaide in Australia Learning $H u b$ Project which was totally co-created with the university students. Accordingly, the higher education market will serve as the context of the current study.

\section{Major Areas of Contributions}

Our intended contribution is to propose and test a coherent and integrated framework that sheds light on consumers' decisions toward involvement in co-creation. Our framework is grounded on a commonly employed theory in contemporary research that is "Theory of planned behavior (TPB) ". Since its introduction, the TBP has been successfully adopted by many scholars to predict and explain people's behaviors in a wide variety of domains. Despite this empirical support for using TPB in contemporary research, little is known if this theory can be applied to the area of value cocreation, and particularly, customers' co-creation experiences. Furthermore, the current study will test the proposed model in experimental setting, which provides more valid and 


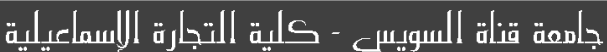

Utility of the theory of planned behavior for predicting ...

Reem Refai Ahmed Mahmoud

reliable findings from which conclusions can be drawn.

\section{Theoretical Framework}

In order to investigate such contemporary complex phenomena as "customers' co-creation experiences", a good strategy would be to identify theories that are valid and adequate for such investigation. For this study, an extended version of the theory of planned behavior (TPB) is used as a framework to guide our proposed customers' co-creation experiences model in the context of the higher education market. The theory of planned behavior integrates several fundamental concepts in the social and behavior disciplines, and it outlines these concepts in a manner that facilitates prediction and understanding of certain behaviors in specified settings (Ajzen, 1991).

\section{The Theory of Planned Behaviour}

The theory of reasoned action predominantly focus on explaining purely volitional simple behaviors where the formation of intention is all what is needed to be done to successfully perform the behavior in question (Ajzen, 1988; Conner and Armitage, 1998). Theory of reasoned action has a very limited capability in predicting behaviors that entails the use of skills, resources, and/or infrequently available 
Utility of the theory of planned behavior for predicting ...

Reem Refai Ahmed Mahmoud

opportunities (Conner and Armitage, 1998). The theory of planned behavior then was developed to handle the insufficiency inherent in its grounded theory, theory of reasoned action. Perceived behavioral control was added as a determinant of both behavioral intention and behavior in the theory of planned behavior (Armitage \& Christian, 2003). The remaining antecedents of intention, attitudes and subjective norms are retained from the earlier theory of reasoned action.

\section{Hypotheses Development and Conceptual Model}

Under the theory of planned behavior, the three antecedents of behavioral intentions are attitudes toward the behavior, subjective norms and perceived behavioral control. Consistent with the theory, we propose that individuals may be more inclined to engage in co-creation activities if they hold positive attitudes toward these activities, if they assume that their significant others would like or approve them to do so, and if they think that they have enough ability and control over such activities. Thus, we propose that:

Consumers: (a) evaluative attitude, (b) subjective norms, and (c) perceived behavioral control mediate the relationship between the level of involvement in co- 
Utility of the theory of planned behavior for predicting ...

Reem Refai Ahmed Mahmoud

\section{creation and behavioral intentions.}

H1.1 Consumers evaluative attitudes mediate the relationship between the level of involvement in co-creation and behavioral intentions.

H1.2 Consumers subjective norms mediate the relationship between the level of involvement in co-creation and behavioral intentions.

\section{H1.3 Consumers perceived behavioral control} mediates the relationship between the level of involvement in co-creation and behavioral intentions.

In addition to the three main antecedents in the TPB, we introduce emotions as a fourth predictor of intentions in our conceptual model. Failure to tap into affect or emotions as a main driver of individuals' decision-making process is one of the major criticisms directed to the TPB. Under the theory attitude is instrumental or evaluative and does not include an affect component. Such addition of a parallel predictor to the original theory is an approach characterized as theory broadening which was employed by many scholars including Ajzan himself (see for instance, Bagozzi and Dholakia 2006). Therefore, we propose that:

H1.4 Consumers positive emotions mediate the relationship between the level of involvement in co-creation 


\section{جاممة قازة السويس - كلية التجارة الإسماعيلية}

Utility of the theory of planned behavior for predicting ...

Reem Refai Ahmed Mahmoud

and behavioral intentions.

\section{Control variables}

To test the research model, several control variables known in the literature to affect either involvement in cocreation or emotional states should be taken into consideration including Level of involvement, familiarity, trust and demographics.

To recap, we propose a new model by deepening the TPB. A new parallel predictor was introduced to the original model. Furthermore, three control variables also were considered in the model, namely trust, involvement and

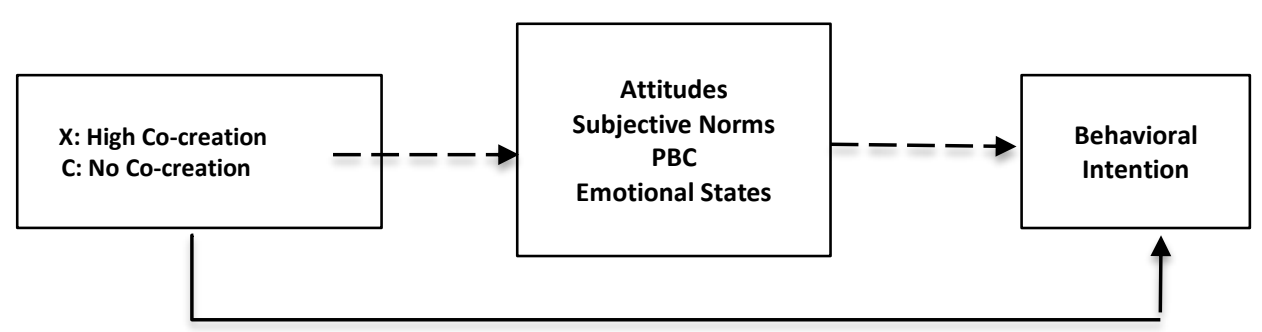

Covariates: Trust, Involvement \& Familiarity.

familiarity (see; Figure 1).

Figure 1 conceptual model 


\section{جاممة قالة السويس - كلية التجارة الإسماعيلية}

Utility of the theory of planned behavior for predicting ...

Reem Refai Ahmed Mahmoud

\section{METHOD}

\section{Participants and design:}

Random sample of 166 participants was recruited from the Paid Subject Pool in the behavioral lab at the Ross School of Business. The research instruments are based on scenario manipulations and questionnaires. Between-subjects experimental design was employed with two treatments group (high co-creation condition vs. low co-creation) and a Control Group (No co-creation).

\section{Realism check:}

Realism of the scenario was mainly assessed by two inquiries via a seven-point Likert type scale adapted from Bagozzi and Dabholkar (1994). The two questions are: how realistic was the scenario description? and how difficult was it for you to project yourself into the scenario?

\section{Manipulation check:}

A manipulation check was conducted to verify whether the respondents understood the co-creation manipulations as intended or not. The efficacy of the manipulation on the independent variable was assessed by two questions based on 7-point Likert type scales are 1) Please indicate the degree of the University librarian and staff involvement/ engagement/ 


\section{جامية قانزة السويست - كلية التجارة إلسماعيلية}

Utility of the theory of planned behavior for predicting ...

Reem Refai Ahmed Mahmoud

participation in planning and designing the trip, and 2) Please indicate the interaction level among the student and university librarian and staff in planning and designing the trip".

\section{$\underline{\text { Experimental Procedures }}$}

Firstly, upon arrival to the behavioral lab each participant was asked to read and sign an IRB (Institutional Review Board) approved consent form. Each of the participants was randomly assigned to one of the experimental conditions. Secondly, Subjects were asked to answer individual differences scales. After that, participants were instructed to, watch an audio-visual presentation of a hypothetical scenario and try to vividly imagine themselves experiencing the situations provided. Subjects were encouraged to watch the AVS of the hypothetical scenario twice in a row to ensure they get a second chance to process the information in the stimulus. After exposure to the stimuli, each participant was asked to fill out a survey with dependent and other variables. 
Utility of the theory of planned behavior for predicting ...

Reem Refai Ahmed Mahmoud

\section{MEASURES}

\section{Manipulation of the Independent Variable}

Co-creation is the research independent variable that is a latent unobserved variable which is hard to measure directly. Therefore, it was operationalized by means of scenario manipulation. Two scenarios/conditions were created, one experimental/treatment condition and one control condition. The treatment condition described co-creation activities taken place between the University of Michigan library and its students. While writing the conditions, the main co-creation dimensions identified by such researchers as Prahalad \& Ramaswamy (2004) and Fuller's (2010) were taken into account. These dimensions include dialogue and interaction among participants, transparency and information sharing between the company and customers, expanding range of customer roles/tasks, availability of multimedia-rich environment and powerful tools, and offering incentives for customers. On the other hand, the control condition used identical descriptive content as employed in the experimental conditions and simply described no co-creation effort undertaking by the university library. Since our research context is the higher education market, the narrative scenarios described co-creation activities with this context (the university library and students). The narrative for both 
Utility of the theory of planned behavior for predicting ...

Reem Refai Ahmed Mahmoud

scenarios went through many pretested and revision trials after the pretests to ensure that they were worded in an appropriate way, to correct for any language mistakes and to reach as realistic a script as possible.

\section{$\underline{\text { Survey Measurement }}$}

Attitudes: four 7-points semantic differential items were employed to measure consumers' attitude regarding engaging in co-creation activities. The four items were useless-useful; ineffective-effective; disadvantageousadvantageous; and bad-good.

Subjective Norms: Bagozzi and Dholakia (2006) 27 points items weremodified and adapted. Participants were asked to express how strongly most people who are important to one feel one should or should not participate in co-creation activities such as the one described in the scenarios. The two items were 1) Most people who are important in my life think I: should 1: 2: 3: 4: 5: 6: 7: should not participate in cocreation activities, 2) Most people who are important to me would: approve 1: 2: 3: 4: 5: 6: 7: disapprove of me participating in co-creation activities.

Perceived behavioral control: Bagozzi and Dholakia (2006) two 7-points items were modified and adapted. The two items are 1) How much control do you have over 
Utility of the theory of planned behavior for predicting ...

Reem Refai Ahmed Mahmoud

participating in co-creation activities such as such as the one described in the scenarios (No control-total control), 2) for me to participate in co-creation activities such as the one described in the scenarios would be (Difficult-Easy scale).

Emotional states: Emotional responses were measured with the query: "As you watched the scenario, please indicate the extent to which you personally felt each of the following emotions". Eight emotional items were listed. Four for negative emotions: unhappy, ashamed, disappointed, and dissatisfied and four items reflecting positive emotions: happy, proud, excited, and pleased. The responses to each item were recorded on five-point scales ranging from 1 (does not describe me at all) to 5 (describe me extremely well).

Behavioral Intentions: Behavioral intentions were measured with the query: "As you watched the scenario, for each of the following statements, please indicate the likelihood that you, personally, would engage in the described activity or behavior in the future. Two items were

1) "If you were to plan for an educational trip in the future, you would collaborate with the university library to plan it as the one described in the video." (5-point "Very Unlikely-Very Likely" scale). 


\section{جاممة قالة السويس - كلية التجارة الإسماعيلية}

Utility of the theory of planned behavior for predicting ...

Reem Refai Ahmed Mahmoud

2) If you were given the opportunity to co-create (produce or design) an educational trip with the university Library, you would be inclined to avoid doing so." (5point "strongly disagree- strongly agree" scale).

Socio-demographic factors: Socio-demographic factors including age, educational level, race, marital status, and household income were recorded.

Familiarity: Participants were asked to answer the two following items using a scale from 0-6:1) "to what extent are you familiar with the concept of co-creation?" 2) "How experienced are you with co-creation activities?"

Trust: Participants were asked to answer the two items using a scale from 0-6:1) "express how much confidence you have that this brand (UMICH Library) will meet your needs, 2) "indicate to what degree you trust that this brand will meet your needs".

Involvement: Delgado-Ballester and Munuera-Alemán (2001) three 5-points semantic differential items were used: For you, please indicate how much the library services are (Unimportant-Important; Means nothing to me- Means a lot to me; Irrelevant-Relevant). 
Utility of the theory of planned behavior for predicting ...

Reem Refai Ahmed Mahmoud

\section{RESULTS}

\section{Sample Description:}

Participants were recruited from the Paid Subject Pool in the behavioral lab of Ross Business School at the University of Michigan. A total of 166 Graduate and undergraduate students participated in the study, of which 141 provide valid responses. The final sample consisted of 49 males $(34.8 \%)$ and 92 females $(65.2 \%)$. The age of participants ranged from 18-32. Each participant was randomly assign either to one of the treatments group (High co-creation Vs. Low co-creation) or to the control group (No co-creation). The final number of participants in each of these groups was 93 participants randomly assigned to one of the two treatment groups (55 in the High co-creation condition and 38 in the low). In addition, 48 participants were randomly assigned to the control group. A total of 25 surveys were considered not valid and discarded from the final sample. The decision to eliminate a survey from further analysis is based on the following criteria:

1) The speed of completing the survey, those who completed the survey very quickly, that is, in less than half of the time required to complete the survey, were eliminated.

2) All straightforward responses were deleted. By straightforward we mean responses with zero standard 
Utility of the theory of planned behavior for predicting ...

Reem Refai Ahmed Mahmoud

deviation that is, they give the same exact answer for all the questionnaire items without exception.

\section{Results of Manipulation \& Realism check:}

Manipulation Check: A one way between groups ANOVA was conducted (after meeting the required assumptions). There were statistically significant differences between the 3 groups $\mathrm{F}_{\text {Librarian }}(2,138)=29.479, \eta^{2}=.29 ; \mathrm{P}<$. $001, \mathrm{~F}_{\text {Interaction }}(2,138)=34.562, \mathrm{P}<.001, \eta^{2}=.38$. The actual difference in mean scores between groups was high. Thus, the two experimental and the control treatments or manipulations appeared to have worked well. Post hoc comparisons using the Bonferroni test, for both manipulation check scales, indicated that the mean square for the high condition was significantly different from the low condition and control group. However, the low condition did not significantly differ from the control group.

Realism Check: Participants were asked about the realism of the scenario and whether they could imagine themselves in such a situation on a 7-point scale (0: unrealistic, 6: very realistic). A one sample t-test against the midpoint of 4 indicated that participants thought the scenario were realistic enough for the high condition and control group but not for the low condition (excluded from regression 


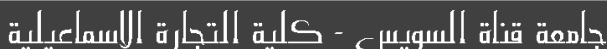

Utility of the theory of planned behavior for predicting ...

Reem Refai Ahmed Mahmoud

model) for this reason, the low group was excluded from further analysis and the total sample reached 103 in the two remaining groups.

\section{Measurement model}

Factor analysis (EFA) was utilized as a means of data reduction. Items with cross loadings (>.25) and low factor loadings $(<.40)$ were eliminated. To assess scales reliability, the internal consistency of the remaining items on each factor (scale sub-dimension) was measured using Cronbach's Alpha. Alpha estimates for each subscale ranged from 0.64 to 0.7 . Thus, overall the measures achieved internal consistency according to acceptable cutoff values indicated in the literature. Turning next to the confirmatory factor analysis, a partial disaggregation model was used to combine items where, items parcels were created by averaging multiple measures (Bagozzi and Dholaki, 2006, P.53).

\section{Hypotheses Testing}

In order to find an indication for the plausibility of using PROCESS moderation mediation models, several diagnostic procedures were followed. We followed three steps:

Step 1. The dataset was tested for the basic regression assumptions (linearity, homoscedasticity, and normality) by 
Utility of the theory of planned behavior for predicting ...

Reem Refai Ahmed Mahmoud

performing the liner regression test on SPSS. The output indicates the assumptions are not violated.

Step 2. Identifying outliers in the data by checking the three distances indicators; Mahalanobis, Cook's, and Leverage values while running the liner multiple regression. A total of the three outliers' indicators were computed to identify cases representing extreme outliers.

Step 3. A collinearity diagnoses was carried out. The two approaches for such diagnoses are correlation coefficients and variance inflation factors (VIFs). For the correlation coefficients, there are no accepted guidelines on what constitute high correlations. Lehmann et al. (1998) suggest 0.9 and Lehmann et al. (1998) advocate 0.7 as a threshold of correlations for collinearity problems (Mela and Kopalle, 2002). All the correlation values are lower than 0.7, which means that collinearity concerns are not serious. For the variance inflation factors, variance inflation factors (VIFs) all values are $(<10)$ indicates that collinearity is not problematic.

The above-mentioned steps provide strong evidence in support for the plausibility of employing regression models for our subsequent analyses, since none of the regression assumptions (i.e., normality, linearity, and homoscedasticity) were seriously violated. 
Utility of the theory of planned behavior for predicting ...

Reem Refai Ahmed Mahmoud

The hypotheses presented earlier were tested within the moderation mediation analysis framework using Hayes PROCESS Macro in SPSS version 21. PROCESS is a computational tool for path analysis-based moderation and mediation analysis as well as their combination as a "conditional process model" (Hayes and Preacher, 2013). Mediation analysis investigates whether a variable (i.e., mediator) changes in regard to an independent variable, in turn, affecting a dependent variable. Moderation analysis, on the other hand, investigates whether the statistical interaction between independent variables predict a dependent variable.

To test the four model mediation variables $\left(\mathrm{Att}_{\mathrm{act}}, \mathrm{SN}\right.$, PBC \& ES) within the PROCESS Macro, "Model 4" was selected. Each mediating variable (M) was tested separately. Behavioral intention was entered as the outcome variable (BI: $\left.\mathrm{Y}_{1}\right)$. Trust, involvement and familiarity were entered as covariates. The manipulation, represented as the two study groups, were dummy coded (Treatment $=1 \&$ Control $=$ Zero) and entered as the independent variable (ManipHC: X) variable. A 10,000-bias corrected bootstrap sampling were requested and covariates in the model were entered as covariates of both $\mathrm{M}$ and $\mathrm{Y}$ variables. The results for each model are provided below. 


\section{جامية قانزة السويسـ - كلية التجارة الالسماعيلية}

Utility of the theory of planned behavior for predicting ...

Reem Refai Ahmed Mahmoud

\section{Evaluative attitude (Att $\underline{\text { act }} \underline{\underline{M_{1}}} \underline{\underline{1}}$}

When entering behavioral intention as the outcome variable $\left(\left(\mathrm{BI}: \mathrm{Y}_{1}\right)\right.$, the total model was significant $\left(R^{2}=.60, F\right.$ $(5,97)=29.44, p<.001)$. The direct effect (c' path) of cocreation on behavioral intentions, after accounting for covariates, was significant $\left(b_{1}=.941, \mathrm{SE}=.250, \mathrm{p}=.0003\right)$. Although path c' was significant, there was a significant indirect effect of co-creation on behavioral intentions through attitudes (effect $\mathrm{a}_{1} * \mathrm{~b}_{1}$ ) as demonstrated by the bootstrapped $95 \%$ confidence interval of the indirect effect, $\left(a_{1} * b_{1}\right)=.79$, $(\mathrm{SE}=.20) ; 95 \% \mathrm{CI}[.44,1.22]$.

\section{Subjective Norms (SN: M2):}

In regard to the role of subjective norms in mediating the relationship between co-creation and behavioral intention, the total model was significant $\left(R^{2}=.53, F(5,97)=21.66, p\right.$ $<.001)$. The direct effect (c' path) of co-creation on behavioral intentions after accounting for covariates was significant $\left(b_{1}=1.69, \mathrm{SE}=.21, \mathrm{p}=.000\right)$. Although path $\mathrm{c}^{\prime}$ was significant, there was no significant indirect effect of cocreation on behavioral intentions through subjective norms (effect $a_{1} * b_{1}$ ), demonstrated by the bootstrapped $95 \%$ CI of the indirect effect, $\left(\mathrm{a}_{1} * \mathrm{~b}_{1}\right)=.04,(\mathrm{SE}=.05) ; 95 \%$ CI $[-.03$, .18].

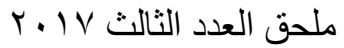




\section{جاممة قالة السويس - كلية التجارة الإسماعيلية}

Utility of the theory of planned behavior for predicting ...

Reem Refai Ahmed Mahmoud

\section{Perceived behavioral control (PBC: M3):}

In regard to the role of $\mathrm{PBC}$ in mediating the relationship between co-creation and behavioral intention, the total model was significant $\left(R^{2}=.52, F(5,97)=20.35, p<\right.$ $.001)$. The direct effect (c' path) of co-creation on behavioral intentions after accounting for covariates was significant $\left(b_{1}=\right.$ $1.72, \mathrm{SE}=.21, \mathrm{p}=.000$ ). Although path $\mathrm{c}^{\prime}$ was significant, there was not significant indirect effect of co-creation on behavioral intentions through PBC (effect $a_{1} * b_{1}$ ), demonstrated by the bootstrapped $95 \%$ CI of the indirect effect, $\left(\mathrm{a}_{1} * \mathrm{~b}_{1}\right)==.01,(\mathrm{SE}=.037) ; 95 \%$ CI $[-.03, .13]$.

\section{Emotional states (EmoP: M4):}

In regard to the role of positive emotional sates in mediating the relationship between co-creation and behavioral intention, the total model was significant $\left(R^{2}=.54, F(5,97)\right.$ $=22.35, p<.001$ ). The direct effect (c'path) of co-creation on behavioral intentions after accounting for covariates was significant $\left(b_{1}=1.29, \mathrm{SE}=.26, \mathrm{p}=.000\right)$. Although path $\mathrm{c}^{\prime}$ was significant, there was a significant indirect effect of cocreation on behavioral intentions through positive emotions (effect $a_{1} * b_{1}$ ), demonstrated by the bootstrapped $95 \%$ CI of the indirect effect, $\left(a_{1}^{*} b_{1}\right)=.44,(\mathrm{SE}=.19): 95 \%$ CI [.110, .87].

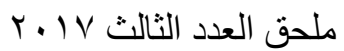




\section{جامية قانة السويسـ - كلية التجارة الالسماعيلية}

Utility of the theory of planned behavior for predicting ...

Reem Refai Ahmed Mahmoud

\section{The overall mediation model:}

A total mediation model was also tested to explore how the four proposed mediators work together in influencing both targeted behavioral outcomes. The results (see table 3) revealed that the co-creation manipulation had a statistically significant impact on both attitudes and emotions but doesn't have such significant impact on SN and PBC. Attitudes were the only constructs that had a significant impact on behavioral intentions.

Table 2 Regression Coefficients and Model Summary for Simple Mediation Models

\begin{tabular}{|c|c|c|c|}
\hline Model 1.1 & b & SE & $\begin{array}{c}\text { P / [LLCI, } \\
\text { ULCI] } *\end{array}$ \\
\hline $\mathrm{X} \rightarrow \mathrm{M}_{1}$ (a) & 1.656 & 0.2034 & $<.001$ \\
\hline $\mathrm{M}_{1} \rightarrow \mathrm{Y}_{1}(\mathrm{~b})$ & 0.4770 & 0.0959 & $<.001$ \\
\hline $\mathrm{X} \rightarrow \mathrm{Y}_{1}(\mathrm{c})$ & 1.713 & .2153 & $<.001$ \\
\hline$X \rightarrow Y_{1}\left(c^{\prime}\right)$ & 0.9412 & 0.2502 & $<.001$ \\
\hline$X \rightarrow M_{1} \rightarrow Y_{1}(a * b)$ & 7901 & 0.1963 & CI $[.438,1.218]$ \\
\hline Overall model: & \multicolumn{3}{|c|}{$R^{2}=.6028, F(5,97)=29.4415, p<.001$} \\
\hline Model 1.2 & b & $\mathrm{SE}$ & $\mathbf{p}$ \\
\hline $\mathrm{X} \rightarrow \mathrm{M}_{2}$ (a) & 0.1427 & 0.1834 & 0.4384 \\
\hline r . I V حد الثالث & & & المجلد الثامن \\
\hline
\end{tabular}




\section{جاممة قالة السويس - كلية التجارة الإسماعيلية}

Utility of the theory of planned behavior for predicting ...

Reem Refai Ahmed Mahmoud

\begin{tabular}{|c|c|c|c|}
\hline $\mathrm{M}_{2} \rightarrow \mathrm{Y}_{1}(\mathrm{~b})$ & 0.2665 & 0.1161 & 0.0239 \\
\hline $\mathrm{X} \rightarrow \mathrm{Y}_{1}(\mathrm{c})$ & 1.713 & 0.2153 & $<.001$ \\
\hline $\mathrm{X} \rightarrow \mathrm{Y}_{1}\left(\mathrm{c}^{\prime}\right)$ & 1.6933 & 0.2114 & $<.001$ \\
\hline $\mathrm{X} \rightarrow \mathrm{M}_{2} \rightarrow \mathrm{Y}_{1}(\mathrm{a} 1 * \mathrm{~b} 1)$ & 0.038 & 0.052 & CI $[-.033, .180]$ \\
\hline Overall model: & \multicolumn{3}{|c|}{$R^{2}=.5272, F(5,97)=21.6358, p<.001$} \\
\hline Model 1.3 & b & SE & $\mathbf{p}$ \\
\hline $\mathrm{X} \rightarrow \mathrm{M}_{3}$ (a) & 0.1184 & 0.2500 & 0.6367 \\
\hline $\mathrm{M}_{3} \rightarrow \mathrm{Y}_{1}(\mathrm{~b})$ & 0.1241 & 0.0865 & 0.1548 \\
\hline $\mathrm{X} \rightarrow \mathrm{Y}_{1}(\mathrm{c})$ & 1.713 & 0.2153 & $<.001$ \\
\hline $\mathrm{X} \rightarrow \mathrm{Y}_{1}\left(\mathrm{c}^{\prime}\right)$ & 1.7166 & 0.2144 & $<.001$ \\
\hline $\mathrm{X} \rightarrow \mathrm{M}_{3} \rightarrow \mathrm{Y}_{1}(\mathrm{a} * \mathrm{~b})$ & 0.014 & 0.037 & CI $[-.033, .130]$ \\
\hline Overall model: & \multicolumn{3}{|c|}{$R^{2}=.5119, F(5,97)=20.3478, p<.001$} \\
\hline Model 1.4 & b & SE & $\mathbf{p}$ \\
\hline $\mathrm{X} \rightarrow \mathrm{M}_{4}(\mathrm{a})$ & 1.3987 & 0.1999 & $<.001$ \\
\hline $\mathrm{M}_{4} \rightarrow \mathrm{Y}_{1}(\mathrm{~b})$ & 0.2804 & 0.1056 & 0.0093 \\
\hline $\mathrm{X} \rightarrow \mathrm{Y}_{1}(\mathrm{c})$ & 1.2872 & .2594 & $<.001$ \\
\hline$X \rightarrow Y_{1}\left(c^{\prime}\right)$ & 1.3391 & 0.2559 & $<.001$ \\
\hline $\mathrm{X} \rightarrow \mathrm{M}_{4} \rightarrow \mathrm{Y}_{1}(\mathrm{a} 1 * \mathrm{~b} 1)$ & .4442 & 0.1933 & CI $[.110, .870]$ \\
\hline Overall model: & \multicolumn{3}{|c|}{$R^{2}=.5354, F(5,97)=22.3526, p<.001$} \\
\hline
\end{tabular}

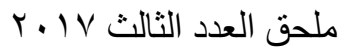




\section{جاممة قناة السويسي - كلية التجارة الإسماعيلية}

Utility of the theory of planned behavior for predicting ...

Reem Refai Ahmed Mahmoud

Table 3 the overall mediation model

\begin{tabular}{|c|c|c|}
\hline Model & b & P/Boot [LLCI, ULCI]* \\
\hline $\mathrm{X} \rightarrow \mathrm{M} 1$ (Att) & 1.6565 & $<.001$ \\
\hline $\mathrm{X} \rightarrow \mathrm{M} 2(\mathrm{SN})$ & .1427 & .4384 \\
\hline $\mathrm{X} \rightarrow \mathrm{M} 3(\mathrm{PBC})$ & .1184 & .6367 \\
\hline $\mathrm{X} \rightarrow \mathrm{M} 4(\mathrm{EmoP})$ & 1.3987 & $<.001$ \\
\hline $\mathrm{M}_{1} \rightarrow \mathrm{Y}_{1}$ & .4107 & $<.001$ \\
\hline $\mathrm{M}_{2} \rightarrow \mathrm{Y}_{1}$ & .1585 & .1549 \\
\hline $\mathrm{M}_{3} \rightarrow \mathrm{Y}_{1}$ & -.0068 & .9345 \\
\hline $\mathrm{M}_{4} \rightarrow \mathrm{Y}_{1}$ & .0890 & .4157 \\
\hline$X \rightarrow Y_{1}(c)$ & .9047 & .001 \\
\hline $\mathrm{X} \rightarrow \mathrm{Y}_{1}\left(\mathrm{c}^{\prime}\right)$ & 1.7313 & .001 \\
\hline $\mathrm{X} \rightarrow \mathrm{M}_{1} \rightarrow \mathrm{Y}_{1}(\mathrm{a} * \mathrm{~b})^{*}$ & .1953 & CI $[.1004, .4038]$ \\
\hline$X \rightarrow M_{2} \rightarrow Y_{1}\left(a^{*} b\right)$ & .0107 & CI $[-.0073, .0505]$ \\
\hline$X \rightarrow M_{3} \rightarrow Y_{1}\left(a^{*} b\right)$ & .0024 & CI $[-.0223, .0146]$ \\
\hline$X \rightarrow M_{4} \rightarrow Y_{1}\left(a^{*} b\right)$ & .0403 & CI $[-.0755, .2054]$ \\
\hline Total Indirect Effect & .3010 & CI $[.1482, .4792]$ \\
\hline
\end{tabular}

\section{Discussion \& Conclusion}

The current study has numerous notable findings. We investigated the indirect effect of co-creation on behavioral 
Utility of the theory of planned behavior for predicting ...

Reem Refai Ahmed Mahmoud

intentions through a group of various mediating variables grounded on theory of planned behavior. We proposed that mediators as attitudes, subjective norms, perceived behavioral control, emotional states could energize behavioral intentions. The current study tested each of the proposed mediators separately. The findings confirmed that attitude is a strong and significant predictor of behavioral intentions, which is consistent with prior studies utilizing theory of planned behavior in similar contexts. However, both subjective norms and perceived behavioral control were not significant predictors for intentions. These findings seem to be inconsistent with some prior studies that have successfully proven both mediators as powerful predictors of behavioral intentions. By contrast to those prior results in support or SN and $\mathrm{PBC}$, numerous prior studies obtained results analogous to our current study. The potential reason for such findings could be related to measurement issues. Furthermore, the lack of support for SN could possibly be attributable to the situation where the behavior is performed. Depending on the context, some co-creation activities can be performed individually via the company online platform requiring indirect and/or lower level of group interaction, which implies lower peer and group pressure. In such cases, subjective norms could have lower impact on intentions.

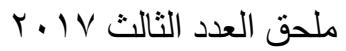
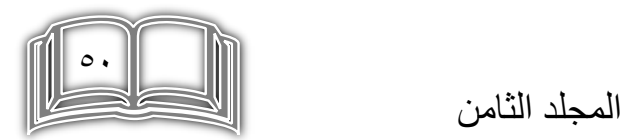
Utility of the theory of planned behavior for predicting ...

Reem Refai Ahmed Mahmoud

Regarding the findings concerning the PBC construct, the current study followed the early practice of Ajzen in treating $\mathrm{PBC}$ as a unidimensional construct. In recent years, however, vast majority of TPB studies have raised the idea that PBC could be conceived of as consisting of two separate but interrelated constructs, namely self-efficacy and controllability (Kraft et al., 2005). The self-efficacy component of PBC deals with the ease or difficulty of performing a behavior, with people's confidence that they can perform it if they want to do so (Kraft et al., 2005, P.481). Theoretical as well as empirical support for the twocomponent model of PBC was reported by some researchers in the area (e.g., Trafimow et al., 2002). Thus, we argue herein that the insignificance of $\mathrm{PBC}$ in predicting co-creation intentions in the current study might be traced to the fact that we employed the unidimensional conceptualization of the PBC construct.

In addition to the original TPB constructs, emotional states were also tested as predictors of intentions and the study results showed support for such a proposition. The impact of positive emotions on intention was significant, which implies that individuals make decision based on their affect, not only based on cognitive or semantic (evaluative) judgments. This result is consistent with the school of thought advocating the importance of affect in guiding intentions and subsequent

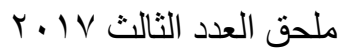

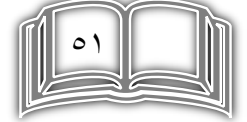

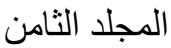




\section{جامية قانزة السويست - كلية التجارة إلسماعيلية}

Utility of the theory of planned behavior for predicting ...

Reem Refai Ahmed Mahmoud

behavior, especially for behaviors considered as altruistic acts such as recycling and blood donation.

Regarding the overall model that encompasses the four proposed mediators in combination, the findings indicated that the co-creation manipulation has a statistically significant impact on both attitudes and emotions but doesn't have a significant impact on SN and PBC. Attitudes in turn were the only constructs that had a significant impact on behavioral intentions. One possible explanation for this result is that the intercorrelations between the variables is relatively high, which implies that multicollinearity produced the effects. However, more research is needed to reach a precise conclusion in this regard.

Table 11 Results of Hypotheses 1 Testing (Mediators)

\begin{tabular}{|l|l|c|}
\hline H1.1 & $\begin{array}{l}\text { Consumers evaluative attitudes mediate the relationship } \\
\text { between the level of involvement in co-creation and } \\
\text { behavioral intentions. }\end{array}$ & Accepted \\
\hline H1.2 & $\begin{array}{l}\text { Consumers subjective norms mediate the relationship } \\
\text { between the level of involvement in co-creation and } \\
\text { behavioral intentions. }\end{array}$ & Rejected \\
\hline H1.3 & $\begin{array}{l}\text { Consumers perceived behavioral control } \text { mediates the } \\
\text { relationship between the level of involvement in co- }\end{array}$ & Rejected \\
\hline
\end{tabular}

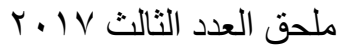

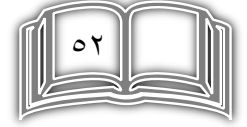

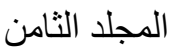


Utility of the theory of planned behavior for predicting ...

Reem Refai Ahmed Mahmoud

\begin{tabular}{|l|l|l|}
\hline & creation and behavioral intentions. & \\
\hline H1.4 & $\begin{array}{l}\text { Consumers positive Emotional states mediate the } \\
\text { relationship between the level of involvement in co- } \\
\text { creation and behavioral intentions. }\end{array}$ & Accepted \\
\hline
\end{tabular}

\section{Limitations and Future Research}

As with most studies, this research has some limitations. The current study outcome variables were likelihood of actions and intention to act as proxy measures for actual behavior. Thus, it has unknown validity in precisely determining the effects of co-creation on actual behavior of consumers. Still, to the degree that the behavioral intentions we did measure are meaningful, we would claim that our current study offers plausibly the most valid and valuable findings until now concerning customers' co-creation experiences. Indeed few studies have empirically tested cocreation, and few studies have used strong theoretical and comprehensive models.

The above-mentioned limitation represents a departure point for future academic research to advance our understanding regarding customer's co-creation experiences, its antecedences and boundary conditions. 
Utility of the theory of planned behavior for predicting ...

Reem Refai Ahmed Mahmoud

\section{References}

Ajzen, I. (1988). Attitudes, personality, and behavior. Chicago: Dorsey Press.

Ajzen, I. (1991). The theory of planned behavior. Organizational behavior and human decision processes, 50 (2), 179-211.

Armitage, C. J., \& Christian, J. (2003). From attitudes to behaviour: Basic and applied research on the theory of planned behaviour. Current Psychology, 22(3), 187-195.

Bagozzi, R. P., \& Dabholkar, P. A. (1994). Consumer recycling goals and their effect on decisions to recycle: A means-end chain analysis. Psychology \& Marketing, 11(4), 313-340.

Bagozzi, R. P., \& Dholakia, U. M. (2006). Antecedents and purchase consequences of customer participation in small group brand communities. International Journal of research in Marketing, 23(1), 4561 .

Conner, M., \& Armitage, C. J. (1998). Extending the theory of planned behavior: A review and avenues for further research. Journal of applied social psychology, 28(15), 1429-1464.

Delgado-Ballester, E., \& Luis Munuera-Alemán, J. (2001). Brand trust in the context of consumer loyalty. European Journal of marketing, 35(11/12), 1238-1258.

Füller, J. (2010). Refining virtual co-creation from a consumer perspective. California management review, 52(2), 98-122.

Galvagno, M., \& Dalli, D. (2014). Theory of value co-creation: a systematic literature review. Managing Service Quality, 24(6), 643-683. 


\section{جامية قانزة السويسـ - كلية التجارة إلسماعيلية}

Utility of the theory of planned behavior for predicting ...

Reem Refai Ahmed Mahmoud

Grönroos, C., \& Voima, P. (2013). Critical service logic: making sense of value creation and co-creation. Journal of the Academy of Marketing Science, 41(2), 133-150.

Gustafsson, A., Kristensson, P., \& Witell, L. (2012). Customer co-creation in service innovation: a matter of communication?. Journal of Service Management, 23(3), 311-327.

Hayes, A. F. (2013). Introduction to mediation, moderation, and conditional process analysis: A regression-based approach. New York: The Guilford Press.

Heidenreich, S., Wittkowski, K., Handrich, M., \& Falk, T. (2015). The dark side of customer co-creation: exploring the consequences of failed cocreated services. Journal of the Academy of Marketing Science, 43(3), 279-296.

Kambil, A., Friesen, G. B., \& Sundaram, A. (1999). Co-creation: A new source of value. Outlook Magazine, 3(2), 23-29.

Kambil, A., Ginsberg, A., \& Bloch, M. (1996). Re-inventing value propositions. Information Systems Working Papers Series, Vol.

Kraft, P., Rise, J., Sutton, S., \& Røysamb, E. (2005). Perceived difficulty in the theory of planned behaviour: Perceived behavioural control or affective attitude?. British Journal of Social Psychology, 44(3), 479-496.

Lehmann D. R., Gupta, S. and Steckel, J. (1988) Marketing Research, Addison-Wesley Educational Publishers, Inc., Reading, Massachussetts.

Prahalad, C. K., \& Ramaswamy, V. (2000). Co-opting customer competence. Harvard business review, 78 (1), 79-90

Prahalad, C. K., \& Ramaswamy, V. (2004). The future of competition. Harvard Business School Press, Boston, MA

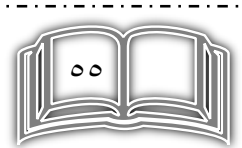




\section{جامoة قناة المسويس - كلية التجلارة الإسماعيلية}

Utility of the theory of planned behavior for predicting ...

Reem Refai Ahmed Mahmoud

Ramaswamy, V., \& Gouillart, F. (2010a). Building the co-creative enterprise. Harvard business review, 88 (10), 100-109.

Trafimow, D., Sheeran, P., Conner, M., \& Finlay, K. A. (2002). Evidence that perceived behavioural control is a multidimensional construct: Perceived control and perceived difficulty. British Journal of Social Psychology, 4l(1), 101-121.

Vargo, S. L., \& Lusch, R. F. (2008). Service-dominant logic: continuing the evolution. Journal of the Academy of marketing Science, 36(1), 1-10. 